\title{
Der Palmengarten auf der 53. Kifissia Flower Show 2007 in Griechenland
}

\author{
Stefan BaCH
}
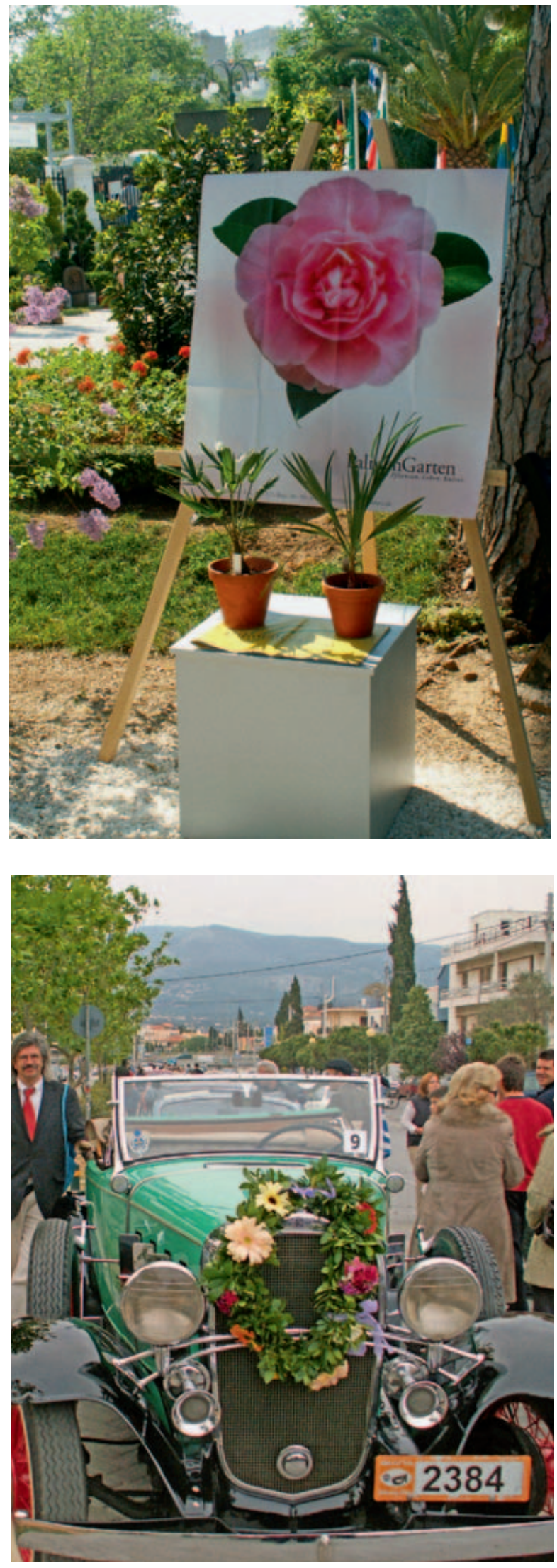

Seit der Teilnahme des Palmengartens an der 52. Kifissia Flower Show 2006 (vgl. Steinecke 2006) wurden verschiedene Kontakte zu griechischen Gartenfreunden vertieft und es findet ein regelmäßiger Erfahrungsaustausch statt. Auch dieses Jahr wurde der Palmengarten wieder zur 53. Flower Show (25.4.-13.5.2007) eingeladen. Im April reiste der Autor als Vertreter des Palmengartens nach Athen. Im Gepäck dabei waren Trachycarpus wagnerianus und Trithrinax campestris, die in Zukunft den botanischen Garten von Athen bereichern werden. Verschiedene Palmengarten-Materialien machten im „Palmengarten-Kiosk“ auch in Griechenland Werbung für Frankfurts schönsten Garten.

Die grüne Blumenstadt Kifissia ist eine Oase im Großraum Athen. Zunehmend interessieren sich Bürgerinnen und Bürger für Natur- und Umweltschutz sowie für die Gestaltung von Gärten. Die traditionelle, seit 1934 jährlich gezeigte Flower Show im Stadtpark von Kifissia zieht deshalb immer mehr Interessenten an.

Begleitend zur Ausstellung gab es ein lehrreiches und unterhaltendes Programm, darunter z. B. wie im Vorjahr einen Oldtimer-Autocorso zur Eröffnung.

In diesem Jahr wurden zahlreiche Aktivitäten speziell für Kinder und junge Besucher angeboten. Außerdem gab es viel über Aufgaben botanischer Gärten zu erfahren. Alle neun botanische Gärten Griechenlands, der Botanische Garten der Universität Wien, der Palmengarten Frankfurt und der Botanische Garten der Universität Sofia beteiligten sich daran.

WWF, Greenpeace, die Technische Schule für Landschaftsplanung in Arta, die griechische Kakteen- und Sukkulentengesellschaft, die griechische Palmengesellschaft und Peliti (Organisation für traditionell genutzte Samen) leisteten

Abb. 1 (oben): „Ein Stückchen Palmengarten“ in Kifissia. Abb. 2 (unten): Der Autor am Oldtimer-Autocorso. 


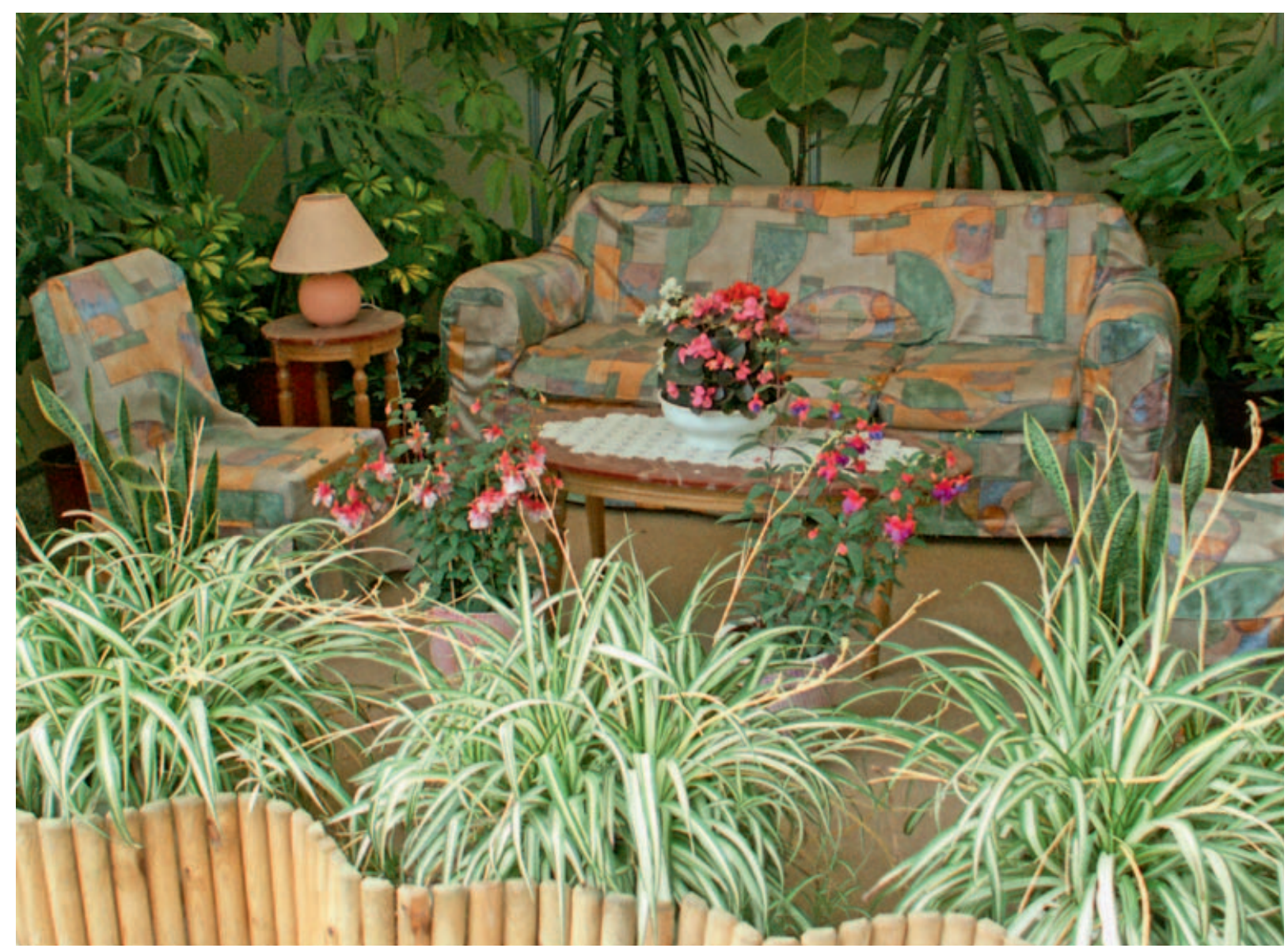

Beiträge zu den Themen Klimaschutz, globales Denken und lokales Handeln. Passend zum LinNÉ-Jahr unterstützte die schwedische Botschaft am 7. Mai einen Beitrag zum berühmten Botaniker CARL vON LINNÉ, wodurch der zunehmend wissenschaftliche Charakter der Blumenschau vertieft wurde. Im Zeitraum der Flower Show fand in Kifissia ein Seminar für Landschaftsarchitekten statt und ein Netzwerk Griechischer Botanischer Gärten wurde gegründet.

Nicolas Chiotaki, Bürgermeister von Kifissia, betonte, dass man mehr für die wachsende Zahl von Leuten tun müsse, die sich Tag für Tag um den Schutz der Umwelt kümmern.

Für den Palmengarten war die Teilnahme an der Flower Show erneut eine gute Gelegenheit, sich auch außerhalb der eigenen Grenzen vorzustellen und neue interessante Kontakte zu Fachkollegen zu knüpfen. Herzlicher Dank gilt

Abb. 3 (oben): Pavillon mit Zimmerpflanzenarrangement. Abb. 4 (unten): Die Blumenkinder kommen.

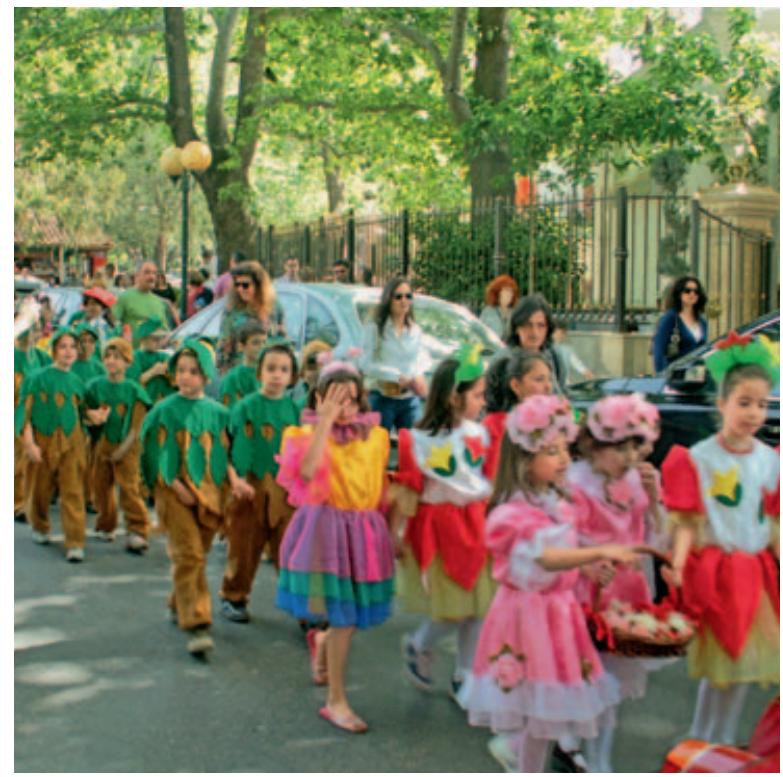

den Olympic Airways, die, wie bereits im letzten Jahr, einen Freiflug nach Athen zur Verfügung gestellt haben.

\section{Literatur}

Steinecke, H. 2006: Der Palmengarten auf der 52. Flower Show in Kifissia bei Athen. - Palmengarten 70: 50-54. 